\title{
ASSESSMENT OF STAGES OF FETAL INFLAMMATORY RESPONSE SYNDROME BY EARLY POSTNATAL INTERLEUKIN-6 AND C-REACTIVE PROTEIN LEVELS IN PRETERM INFANTS
}

\author{
K. Inomata, S. Iwatani, Y. Kishida, H. Sakai, M. Mizobuchi, S. Yoshimoto, H. Nakao \\ Department of Neonatology, Kobe Children's Hospital Perinatal Center, Kobe, Japan
}

Background and aims: The early postnatal changes in interleukin-6 (IL-6) and C-reactive protein (CRP) levels in preterm infants born after fetal inflammatory response syndrome (FIRS) have not been studied extensively. The aim was to determine the stages of FIRS by measuring IL- 6 and CRP on day 0 and 2 in preterm infants.

Methods: Among 100 infants of less than 32 weeks' gestation, 30 had elevated levels of IL-6 ( $\geqq 500 \mathrm{pg} / \mathrm{ml})$ on day 0 . Of the 30 infants, 8 were positive for CRP ( $\geqq 0.5 \mathrm{mg} / \mathrm{dl})$ (CRP-positive group) and 22 were negative (CRP-negative group). The changes in the levels of IL- 6 and CRP between day 0 and day 2 , and the perinatal factors were compared between the two groups.

Results: The levels of CRP were increased significantly from $0.02 \mathrm{mg} / \mathrm{dL}$ on day 0 to $0.71 \mathrm{mg} / \mathrm{dL}$ on day 2 in the CRP-negative group, whereas the levels of CRP unchanged in the CRP-positive group. The levels of IL-6 decreased significantly from day 0 to day 2 in both groups. Platelet counts were significantly lower in the CRP-positive group than those in the CRP-negative group. The incidence of positive nasal culture was significantly higher in the CRP-positive group than that in the CRP-negative group (63\% vs. $0 \%$ ).

Conclusions: The assessment of early postnatal changes in IL-6 and CRP levels is useful for determining the stages of FIRS in preterm infants. The elevated levels of CRP on day 0 may represent subacute phase of FIRS and associate with an increased risk of congenital infection. 